\title{
Mechanical Performance and Stress-Strain Relationships for Grouted Splices Under Tensile and Cyclic Loadings
}

\author{
Feng Lin*, and Xiaobao Wu
}

(Received January 4, 2016, Accepted May 30, 2016, Published online June 28, 2016)

\begin{abstract}
Experimental studies were conducted on 36 grouted splices to investigate their mechanical performance under four loading schemes: (1) incremental tensile loading, (2) repeated tensile loading, (3) cyclic loading at high stress, and (4) cyclic loading at large strain. Load-deformation responses of the grouted splices under cyclic loadings were featured with pinching effect and stiffness degradation compared to those responses under tensile loadings. The shape of the hysteresis loops of load-deformation curves was similar to that under incremental tensile loading. For the purpose of structural analysis, stress-strain relationships were presented for grouted splices under various loadings.
\end{abstract}

Keywords: sleeve connector, grouted splice, cyclic loading, stress-strain relationship.

\section{List of Symbols}

$d$

E

$E_{1}$

$E_{2}$

$E_{3}$

$E_{4}$

$E_{\mathrm{g}}$

$E_{\mathrm{h}}$

$E_{\mathrm{s}}$

$f_{\text {cg }}$

$f_{\text {tg }}$

$f_{\mathrm{u}}$

$f_{\text {us }}$

$f_{\mathrm{y}}$

$f_{\text {ys }}$

$F_{\text {ys }}$

L

$L_{1}$

$L_{2}$

$L_{3}$

$L_{\mathrm{IT}}$

$L_{\mathrm{RT}}$

$P_{\mathrm{u}}$
Bar diameter

Elasticity modulus of a splice under first loading

Modulus of a splice under reloading

Modulus of a splice under positive unloading

Modulus of a splice under negative loading

Modulus of a splice under negative unloading

Elasticity modulus of grout

Modulus of a splice in hardening stage

Elasticity modulus of reinforcing steel bar

Axial compressive strength of grout using prisms $70.7 \times 70.7 \times 230 \mathrm{~mm}$

Tensile strength of grout

Ultimate stress of embedded bar of a splice

Ultimate strength of reinforcing steel bar

Yield strength of a splice

Yield strength of reinforcing steel bar

Force corresponding to the yield strength of connected bars

Sleeve length

Embedded length of bar in wide end

Embedded length of bar in narrow end

Gauge length, $L_{3}=L+4 d$

Deformed length within gauge length of $L_{3}$ at ultimate load of an IT-series splice

Deformed length within gauge length of $L_{3}$ at ultimate load of a RT-series splice

Ultimate load

Department of Structural Engineering, Tongji

University, Shanghai 200092, People's Republic of China.

*Corresponding Author; E-mail: lin_feng@tongji.edu.cn

Copyright $($ The Author(s) 2016. This article is published

with open access at Springerlink.com $t$

$u_{4}$

$u_{8}$

$u_{20}$

$u_{\mathrm{IT}}$

$u_{\mathrm{RT}}$

$\alpha_{\mathrm{f}}$

$\alpha_{f}^{\prime}$
$\delta_{4}$

$\delta_{8}$

$\delta_{20}$

$\delta_{\mathrm{IT}}$

$\delta_{\mathrm{RT}}$

$\varepsilon_{\mathrm{A}}, \varepsilon_{\mathrm{C}}$,

$\varepsilon_{\mathrm{D}}, \varepsilon_{\mathrm{A}^{\prime}}$,

$\varepsilon_{\mathrm{C}^{\prime}}$, and $\varepsilon_{\mathrm{D}^{\prime}}$

$\varepsilon_{\mathrm{u}}$

$\varepsilon_{\text {us }}$

$\varepsilon_{\mathrm{ys}}$

$\sigma_{\mathrm{A}}, \sigma_{\mathrm{C}}$,

$\sigma_{\mathrm{D}}, \sigma_{\mathrm{A}^{\prime}}$,

$\sigma_{\mathrm{C}^{\prime}}, \sigma_{\mathrm{D}^{\prime}}$

$\sigma_{\mathrm{L}}, \sigma_{\mathrm{M}}$

and $\sigma_{\mathrm{H}}$
Thickness of the stop in a sleeve

Residual deformation after loading reversing four times of a CL-series splice

Residual deformation after loading reversing eight times of a CL-series splice

Residual deformation after loading reversing 20 times of a $\mathrm{CH}$-series splice

Elongation of an IT-series splice at ultimate load

Elongation of a RT-series splice at ultimate load

Stress coefficient due to negative friction

Stress coefficient due to positive friction

Relative residual deformations after loading reversing four times of a CL-series splice

Relative residual deformation after loading reversing eight times of a CL-series splice

Relative residual deformation after loading reversing 20 times of a $\mathrm{CH}$-series splice

Relative elongation at ultimate load of an ITseries splice

Relative elongation at ultimate load of a RTseries splice

Splice strain of points A, C, D, A', C', and $\mathrm{D}^{\prime}$, respectively

Ultimate strain of a splice

Ultimate strain of reinforcing steel bar

Yield strain of reinforcing steel bar

Splice stress of points A, C, D, A', C', D', L,

$\mathrm{M}$, and $\mathrm{H}$, respectively 
$\Delta \varepsilon$

$\Delta \varepsilon_{+}$

$\Delta \varepsilon_{\mathrm{y}}$

$\Delta \varepsilon_{\mathrm{ys}}$

$\Phi_{1}$

$\Phi_{2}$
Average bond strength, $\tau_{\mathrm{u}}=P_{\mathrm{u}} /\left(\pi d L_{\mathrm{i}}\right), L_{\mathrm{i}}$ with $i=1$ or 2 means the length of embedded bar that was pulled out

Horizontal strain length under negative loading due to the pinching effect

Horizontal strain length under positive loading due to the pinching effect

Yield plateau length of a splice

Yield plateau length of reinforcing steel bar

Diameter of wide end of a sleeve

Diameter of narrow end of a sleeve

\section{Introduction}

The most commonly used methods to splice reinforcing steel bars are lap splices, welded splices and mechanical connections. Since the 1970s when grouted splices (to be referred to as splices from this point forward) were invented (Yee 1973), they have been used as a preferred technology to splice bars particularly in precast concrete elements. This type of splice can provide continuity of reinforcement between precast elements and develop quality connections maintaining structural integrity. Figure 1 illustrates a splice of typical configuration. The grout-filled coupling sleeve came in different sizes to splice reinforcing bars of the adjacent precast members. Ribs were produced on the sleeve's interior surface to increase the resistance force of the bond between the sleeve and grout. A stop located in the sleeve's midsection ensures appropriate positioning of the two embedded bars. On construction sites, high-strength and non-shrink cementitious grout was cast into the sleeve and around the bars using a low-pressure grout pump. By doing this, lateral confinement to the bars was generated to enhance the grout-bar bond, resulting in a transfer of axial force between discontinued bars.

Efforts have been conducted to investigate the mechanical performance of splices with coupling sleeves of various geometrical and mechanical configurations, mostly under incremental tensile loading. In general, the most common failure modes for splices under incremental tensile loading have been bar fracture and bar pull-out due to grout-bar bond failure (Einea et al. 1995; Jansson 2008; Ling et al. 2012). In these circumstances, the mechanical performance of the splices essentially depends on the bond behavior between grout and bars. Test results have indicated that the mechanical performance of the splices is generally not as strong as that of the connected bars. For example, the tensile strengths and deformation capacities of the splices were lower than those of the connected bars (Einea et al. 1995; Ling et al. 2012; Kim and Lee 2012; Ling et al. 2014; Henin and Morcous 2015), e.g., the ultimate strengths and ultimate strains of 24 specimens appropriately fabricated by Ling et al. (2014) averaged 95 and $62 \%$ of those of the connected bars, respectively. In general, appropriate geometrical configuration of coupling sleeves, adequate embedded length of bars, and high compressive strength of grout help to enhance the groutbar bond and, therefore, improve the mechanical performance of the splices. On the other hand, limited information is available for the behavior of splices under cyclic loading. Hayashi et al. (1997) studied strength, rigidity, capacity of elongation, and the bond stress-slip relationship of splices under cyclic loading. The loading reversed 20 loops and ranged from $0.95 F_{\mathrm{ys}}$ in tension to $-0.5 F_{\mathrm{ys}}$ in compression, where $F_{\text {ys }}$ denotes the force corresponding to the yield strength of the connected bars. They found that the mechanical performance of the splices improved with an increase in embedded length of bars and compressive strength of grout.

Despite these efforts, data are still scarce on the mechanical performance of splices, especially those involved in cyclic loadings when the splices are considered for use in earthquake-prone areas. Moreover, stress-strain relationships for splices under various loading schemes have not been available, which has made it difficult to build accurate models to simulate and to understand the behavior of

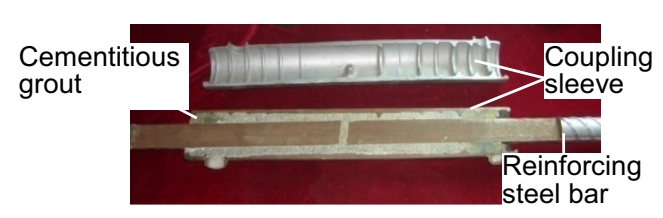

\begin{tabular}{l|c|c|c|c}
\hline Geometric & \multicolumn{4}{|c}{ Sleeve size } \\
\cline { 2 - 5 } parameter & 5VSA & 7 VSA & 8VSA & 10VSA \\
\hline \hline$d[\mathrm{~mm}]$ & $14-16$ & $20-22$ & 25 & 32 \\
\hline$\Phi_{1}[\mathrm{~mm}]$ & 31 & 43 & 47 & 54 \\
\hline$\Phi_{2}[\mathrm{~mm}]$ & 20 & 27 & 31 & 39 \\
\hline$L_{1}[\mathrm{~mm}]$ & 94 & 129 & 144 & 185 \\
\hline$L_{2}[\mathrm{~mm}]$ & 101 & 136 & 151 & 192 \\
\hline$L[\mathrm{~mm}]$ & 220 & 290 & 320 & 403 \\
\hline$t[\mathrm{~mm}]$ & 5 & 5 & 5 & 6 \\
\hline
\end{tabular}

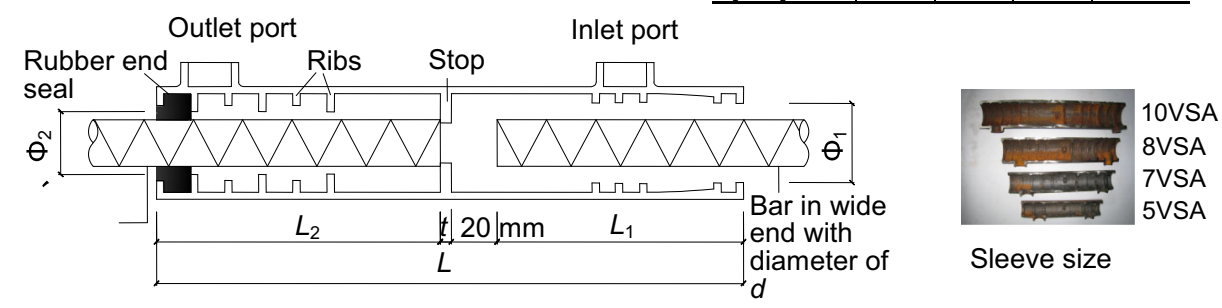

$d$ : diameter of steel bars; $\Phi_{1}$ : diameter of wide end; $\Phi_{2}$ : diameter of narrow end; $L_{1}$ and $L_{2}$ : embedded length of bar in wide and narrow end, respectively; $L$ : sleeve length; $t$ : thickness of stop

Fig. 1 Grouted splice of typical configuration used in this study. 
structural components and structures (Ren et al. 2015; Ameli et al. 2015). In fact, most of the technical details for this type of product are private and proprietary with restricted access. In this regard, tests on a total of 36 specimens were conducted in this study to gain new knowledge on the characteristics of the splices under tensile and cyclic loadings. Special attention was paid to the deformation capacities of the splices and the association of the mechanical performance of the splices under different loadings. Stress-strain relationships were presented for splices under various loadings.

Four loading schemes were used in this study, i.e., incremental tensile (IT) loadings and repeated tensile (RT) loadings as well as cyclic loadings at high stress $(\mathrm{CH})$ and at large strain (CL). The second loading scheme (RT) relates to a splice under service loads with a stress level of generally no more than $60 \%$ of the yield strength of the spliced bars. The third and fourth loading schemes ( $\mathrm{CH}$ and $\mathrm{CL}$ ) are of special interest because they involve splices under frequent and rare earthquakes, respectively. Commonly, the stress level of the splices under frequent earthquakes did not exceed the bar's yield strength. However, for the splices under rare earthquakes, the stress level of the splices generally can go beyond the bar's yield strength and large plastic strain could occur. As a result, $90 \%$ of the bar's yield strength and two to five times of the bar's yield strain in tension were defined as high stress and large strain, respectively, along with reversed loading of up to $33 \%$ of the bar's yield strength in compression.

\section{Experimental Program}

\subsection{Materials and Specimen Fabrication}

The splice specimens consisted of three components of various types, i.e., four sizes of coupling sleeves (5VSA, 7VSA, 8VSA and 10VSA), grout, and two grades of reinforcing steel bars (HRB400 and HRB500). The coupling sleeves and grout used in this study were manufactured by a producer and are commercially available. The sleeves were cast of ductile iron with a specified tensile strength and relative elongation of no less than $600 \mathrm{MPa}$ and $3 \%$, respectively (JGJ355-2015 2015). The four sizes of the coupling sleeves with specific geometric parameters, as presented in Fig. 1, were used for different diameters of connected bars. The left part with a length of $L_{2}$ and right part with a length of $L_{1}$ for each coupling sleeve were not similar and thus the product was non-symmetrical. The left and right parts were associated with an outlet port and inlet port, respectively. This profile made it easy to embed bars and ensure the quality of casting grout. The prepackaged grout was mixed per the manufacturer's instructions with a fluidity of 180-270 mm for easy operation. Tables 1 and 2 present the mechanical properties of the reinforcing steel bars and grout at 28 days obtained by testing. All data in the tables represent the mean values of the results of three specimens. Obviously, the strengths of the bar grade HRB500 are higher than those of HRB400. In fabrication of the splices, the sleeves were first placed vertically by means of fixture. The bars were then carefully inserted into the

Table 1 Mechanical properties of reinforcing steel bars.

\begin{tabular}{|c|c|c|c|c|c|c|c|}
\hline Grade & Diameter $d(\mathrm{~mm})$ & $\begin{array}{c}\text { Yield strength } f_{\mathrm{ys}} \\
(\mathrm{MPa})\end{array}$ & $\begin{array}{c}\text { Ultimate strength } \\
f_{\text {us }}(\mathrm{MPa})\end{array}$ & $\begin{array}{c}\text { Elasticity } \\
\text { modulus } E_{\mathrm{s}} \\
\left(\times 10^{5} \mathrm{MPa}\right)\end{array}$ & $\begin{array}{c}\text { Ultimate strain } \\
\varepsilon_{\mathrm{us}}\end{array}$ & $\begin{array}{l}\text { Yield plateau } \\
\text { length }^{\mathrm{a}} \Delta \varepsilon_{\mathrm{ys}}\end{array}$ & $f_{\mathrm{us}} / f_{\mathrm{ys}}$ \\
\hline \multirow[t]{7}{*}{ HRB400 } & 14 & 532 & 656 & 1.89 & 0.12 & 0.022 & 1.23 \\
\hline & 16 & 551 & 685 & 1.97 & 0.11 & 0.017 & 1.24 \\
\hline & 20 & 427 & 569 & 1.79 & 0.15 & 0.016 & 1.33 \\
\hline & 22 & 503 & 675 & 2.15 & 0.13 & 0.016 & 1.34 \\
\hline & 25 & 519 & 657 & 2.13 & 0.12 & 0.019 & 1.27 \\
\hline & 32 & 424 & 586 & 1.84 & 0.12 & 0.012 & 1.38 \\
\hline & Mean value & 493 & 638 & 1.96 & 0.13 & 0.017 & 1.30 \\
\hline \multirow[t]{7}{*}{ HRB500 } & 14 & 605 & 741 & 2.11 & 0.12 & 0.017 & 1.22 \\
\hline & 16 & 615 & 768 & 1.82 & 0.12 & 0.015 & 1.25 \\
\hline & 20 & 619 & 765 & 2.18 & 0.11 & 0.012 & 1.24 \\
\hline & 22 & 597 & 755 & 1.90 & 0.11 & 0.015 & 1.27 \\
\hline & 25 & 571 & 733 & 2.00 & 0.12 & 0.015 & 1.28 \\
\hline & 32 & 555 & 719 & 1.85 & 0.12 & 0.017 & 1.30 \\
\hline & Mean value & 594 & 747 & 1.98 & 0.12 & 0.015 & 1.26 \\
\hline
\end{tabular}

\footnotetext{
${ }^{a}$ Hot-rolled steel bars HRB400 and HRB500 exhibit approximate horizontal segment after yielding in their stress-strain curves.
} 
Table 2 Mechanical properties of grout.

\begin{tabular}{c|c|c}
\hline $\begin{array}{c}\text { Axial compressive } \\
\text { strength } f_{\mathrm{cg}}(\mathrm{MPa})^{*}\end{array}$ & $\begin{array}{c}\text { Elasticity modulus } E_{\mathrm{g}} \\
\left(\times 10^{4} \mathrm{MPa}\right)\end{array}$ & $\begin{array}{c}\text { Tensile strength } f_{\mathrm{tg}} \\
(\mathrm{MPa})\end{array}$ \\
\hline \hline 84 & 2.9 & 3.5 \\
\hline
\end{tabular}

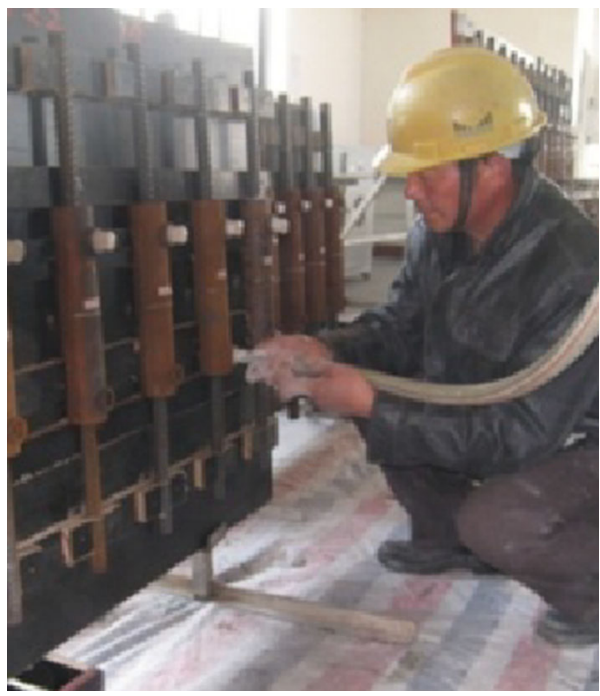

Fig. 2 Pouring grout in splice specimens.

sleeves from their two ends to make the two bars line up as accurately as possible. Ring-form rubber end seals were affixed to the narrow end of each coupling sleeve to prevent grout leakage. Afterwards, the grout was poured in the sleeves from inlet ports using a grout pump, as illustrated in Fig. 2. Finally, the splice specimens were removed from the fixture after $24 \mathrm{~h}$ and horizontally placed at room temperature for about 28 days until testing.

\subsection{Specimens Under Incremental and Repeated Tensile Loadings}

Table 3 presents details of 24 IT- and RT-series specimens. For each loading scheme, the test plan included two grades of bars with six different diameters. Table 4 shows the loading procedures by reference to the Chinese code (JGJ355-2015 2015). These loading procedures were also similar to the international acceptance criteria AC133 (2014) but not identical. A $500 \mathrm{kN}$ servo-hydraulic actuator with an accuracy of $2 \mathrm{kN}$ was used for loading. Figure 3 illustrates the test setup, arrangement of the displacement transducers and strain gauges. The measured data included loading forces, sleeve strains, and splice deformations within gauge length of $L_{3}\left(L_{3}=L+4 d\right.$, where $L$ and $d$ denote sleeve length and bar diameter, respectively). The gauge length of $L_{3}$ was used in the Chinese code JGJ355-2015 and uniformly adopted for all 36 specimens in this study for the sake of comparison. The loading forces were recorded automatically by a data acquisition device of the actuator. For each coupling sleeve, its strain distribution was investigated by sticking strain gauge rosettes, $s p_{1}$ to $s p_{6}$, along the length of its external surface. Two displacement transducers with an accuracy of $0.01 \mathrm{~mm}$ were used for each specimen and their average values were applied to obtain deformations. As a result, the relative elongations at ultimate loads $\delta_{\text {IT }}$ of the ITseries splices are calculated by means of the elongations, $u_{\mathrm{IT}}$, and deformed length within the gauge length of $L_{3}, L_{\mathrm{IT}}$, using Eq. (1):

$$
\delta_{\mathrm{IT}}=\frac{u_{\mathrm{IT}}}{L_{3}}, \text { with } u_{\mathrm{IT}}=L_{\mathrm{IT}}-L_{3}
$$

Similarly, the relative elongations at ultimate loads $\delta_{\mathrm{RT}}$ of the RT-series specimens are calculated by means of the elongations, $u_{\mathrm{RT}}$, and deformed length within the gauge length of $L_{3}, L_{\mathrm{RT}}$, using Eq. (2):

$$
\delta_{\mathrm{RT}}=\frac{u_{\mathrm{RT}}}{L_{3}}, \text { with } u_{\mathrm{RT}}=L_{\mathrm{RT}}-L_{3}
$$

The relative elongations $\delta_{\mathrm{IT}}$ and $\delta_{\mathrm{RT}}$ gave mean values similar to the ultimate strains of bars. The loading force was controlled with a stress rate of about $30 \mathrm{MPa} / \mathrm{s}$ before bar yielding and beyond that transferred to displacement control with a strain rate of about $0.002 \mathrm{~s}$. Deformations within the gauge length rather than $L_{3}$ were also measured for another research purpose, which is not presented herein.

\subsection{Specimens Under Cyclic Loading at High Stress and at Large Strain}

Table 5 presents details of the CH- and CL-series specimens. For each loading scheme, the test plan included two grades of bars with three typical diameters, i.e., small, medium and large diameters of 16,25 and $32 \mathrm{~mm}$, respectively.

Table 6 shows the loading procedures and to be measured residual deformations $u_{20}, u_{4}$ and $u_{8}$ (JGJ355-2015 2015). A $2000 \mathrm{kN}$ servo-hydraulic actuator with an accuracy of $2 \mathrm{kN}$ was used and illustrated in Fig. 4, because this machine can apply loading in a cyclic way. The ways to obtain these data and loading rules were identical to those under incremental and repeated tensile loadings. The relative residual deformations $\delta_{20}, \delta_{4}$ and $\delta_{8}$ of the splices can be calculated using Eqs. (3)-(5), respectively:

$$
\begin{aligned}
& \delta_{20}=\frac{u_{20}}{L_{3}} \\
& \delta_{4}=\frac{u_{4}}{L_{3}} \\
& \delta_{8}=\frac{u_{8}}{L_{3}}
\end{aligned}
$$

where $u_{20}$ is the residual deformation of the $\mathrm{CH}$-series specimens while $u_{4}$ and $u_{8}$ denote the residual deformations of the CL-series specimens. The relative residual deformations describe the effect of cyclic loading on the deformations of the splices. 
Table 3 Details of specimens under incremental and repeated tensile loadings.

\begin{tabular}{|c|c|c|c|c|c|}
\hline Loading scheme & Specimen No. & Bar grade & Bar diameter $(\mathrm{mm})$ & Sleeve size & Sleeve length $L(\mathrm{~mm})$ \\
\hline \multirow{12}{*}{$\begin{array}{l}\text { Incremental tensile } \\
\text { loading }\end{array}$} & IT-H400D14 & \multirow[t]{6}{*}{ HRB400 } & 14 & 5VSA & 220 \\
\hline & IT-H400D16 & & 16 & $5 \mathrm{VSA}$ & 220 \\
\hline & IT-H400D20 & & 20 & $7 \mathrm{VSA}$ & 290 \\
\hline & IT-H400D22 & & 22 & 7VSA & 290 \\
\hline & IT-H400D25 & & 25 & $8 \mathrm{VSA}$ & 320 \\
\hline & IT-H400D32 & & 32 & $10 \mathrm{VSA}$ & 403 \\
\hline & IT-H500D14 & \multirow[t]{6}{*}{ HRB500 } & 14 & $5 \mathrm{VSA}$ & 220 \\
\hline & IT-H500D16 & & 16 & $5 \mathrm{VSA}$ & 220 \\
\hline & IT-H500D20 & & 20 & 7VSA & 290 \\
\hline & IT-H500D22 & & 22 & 7VSA & 290 \\
\hline & IT-H500D25 & & 25 & $8 \mathrm{VSA}$ & 320 \\
\hline & IT-H500D32 & & 32 & $10 \mathrm{VSA}$ & 403 \\
\hline \multirow{12}{*}{$\begin{array}{c}\text { Repeated tensile } \\
\text { loading }\end{array}$} & RT-H400D14 & \multirow[t]{6}{*}{ HRB400 } & 14 & $5 \mathrm{VSA}$ & 220 \\
\hline & RT-H400D16 & & 16 & $5 \mathrm{VSA}$ & 220 \\
\hline & RT-H400D20 & & 20 & 7VSA & 290 \\
\hline & RT-H400D22 & & 22 & 7VSA & 290 \\
\hline & RT-H400D25 & & 25 & $8 \mathrm{VSA}$ & 320 \\
\hline & RT-H400D32 & & 32 & $10 \mathrm{VSA}$ & 403 \\
\hline & RT-H500D14 & \multirow[t]{6}{*}{ HRB500 } & 14 & $5 \mathrm{VSA}$ & 220 \\
\hline & RT-H500D16 & & 16 & $5 \mathrm{VSA}$ & 220 \\
\hline & RT-H500D20 & & 20 & 7VSA & 290 \\
\hline & RT-H500D22 & & 22 & 7VSA & 290 \\
\hline & RT-H500D25 & & 25 & $8 \mathrm{VSA}$ & 320 \\
\hline & RT-H500D32 & & 32 & $10 \mathrm{VSA}$ & 403 \\
\hline
\end{tabular}

Table 4 Loading procedures for specimens under incremental and repeated tensile loadings.

\begin{tabular}{|c|c|}
\hline Loading scheme & Loading procedure \\
\hline \multirow[t]{2}{*}{ Incremental tensile loading } & $0 \rightarrow$ ultimate load $\rightarrow$ (measuring elongation at ultimate load, $u_{\mathrm{IT}}$ ) \\
\hline & 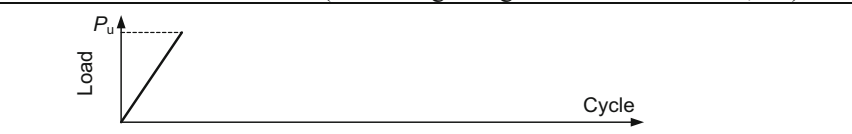 \\
\hline \multirow[t]{2}{*}{ Repeated tensile loading } & $\begin{aligned} 0 \rightarrow 0.6 F_{\mathrm{ys}}{ }^{*} \rightarrow & 0.02 F_{\mathrm{ys}} \rightarrow 0.6 F_{\mathrm{ys}} \rightarrow \\
& \text { (measuring elongation at ultimate load, } u_{\mathrm{RT}} \text { ) }\end{aligned}$ \\
\hline & $\stackrel{\substack{\sigma \\
\stackrel{\sigma}{0}} 0.6 F_{\mathrm{ys}}}{0.02 F_{\mathrm{ys}}}$ \\
\hline
\end{tabular}

\footnotetext{
* $F_{\mathrm{ys}}$ is the loaded force corresponding to the yield strength of the connected bars.
} 

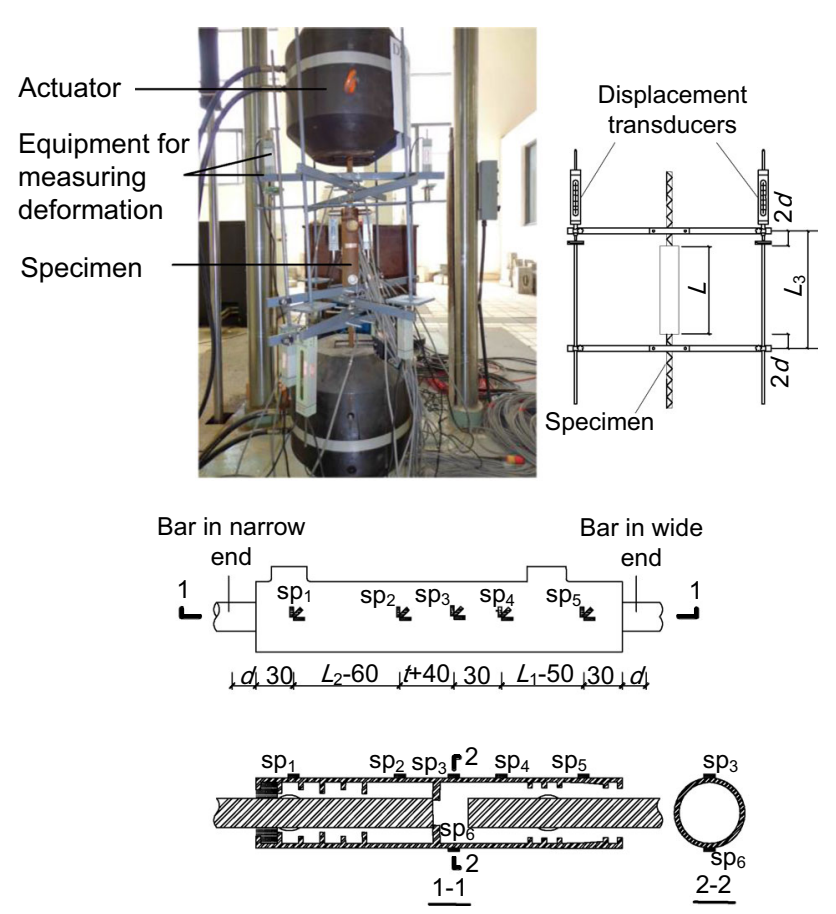

Fig. 3 Test setup, arrangement of displacement transducers and strain gauges for specimens under incremental and repeated tensile loadings.

\section{Test Results}

\subsection{Specimens Under Incremental and Repeated Tensile Loadings}

Table 7 summarizes the test results of the IT- and RTseries specimens.

\subsubsection{Failure Modes}

Two failure modes were observed and illustrated in Fig. 5, i.e., bar fracture and bar pull-out due to grout-bar bond failure. For the bar pull-out failure, a block of cone-shaped grout with an angle of about $45^{\circ}$ was pulled out of the bar.
Table 7 presents the failure mode for each specimen. These two failure modes were also observed in previous studies (Einea et al. 1995; Jansson 2008; Ling et al. 2012). Other failure modes found in these three references, e.g., sleeve tensile failure and grout-sleeve bond failure, did not occur in this study. This was probably because, in the current study, the coupling sleeve and grout-sleeve bond provided relatively strong resistance compared to the resistance offered by the connected bars and grout-bar bond. As a result, sleeve tensile failure and grout-sleeve bond failure were prevented.

\subsubsection{Ultimate Loads}

Failure modes have revealed that the ultimate load of a specimen depends on two factors, i.e., the ultimate tension of the bar and the resistance force provided by the grout-bar bond, of which is weaker. Table 7 also indicates that the ultimate loads $P_{\mathrm{u}}$ of the specimens using the HRB500 reinforcing steel bar were greater than those that used the HRB400 bar. In general, this observation was explicable when associated with the two failure modes. The failure mode of the bar fracture involved the specimens using the HRB400 and HRB500 reinforcing steel bars with their diameter of $14 \mathrm{~mm}$. The failure mode of the bar pull-out included specimens with a diameter of 22,25 and $32 \mathrm{~mm}$. For the bar fracture, the ultimate loads depended on the ultimate strengths of the connected bars. Therefore, the ultimate loads of the specimens using the HRB500 reinforcing steel bars were greater than those of the HRB400 bars because the ultimate strength of a HRB500 bar is higher than that of a HRB400 bar with identical diameter. For the bar pull-out failure, the average bond strength of the HRB400 bar is less than that of the HRB500 bar because the low yield strength of the HRB400 bars comes along with a low average bond strength (Steuck et al. 2009). The local bond stresses were reduced by two effects related to the yielding of reinforcing steel bars. First, the large bar strains associated with yielding increase the slip of the bar from the

Table 5 Details of specimens under cyclic loadings at high stress and at large strain.

\begin{tabular}{|c|c|c|c|c|c|}
\hline Loading scheme & Specimen No. & Bar grade & Bar diameter $(\mathrm{mm})$ & Sleeve size & Sleeve length $L(\mathrm{~mm})$ \\
\hline \multirow{6}{*}{$\begin{array}{c}\text { Cyclic loading at high } \\
\text { stress }\end{array}$} & CH-H400D16 & \multirow[t]{3}{*}{ HRB400 } & 16 & $5 \mathrm{VSA}$ & 220 \\
\hline & CH-H400D25 & & 25 & $8 \mathrm{VSA}$ & 320 \\
\hline & CH-H400D32 & & 32 & $10 \mathrm{VSA}$ & 403 \\
\hline & CH-H500D16 & \multirow[t]{3}{*}{ HRB500 } & 16 & $5 \mathrm{VSA}$ & 220 \\
\hline & $\mathrm{CH}-\mathrm{H} 400 \mathrm{D} 25$ & & 25 & $8 \mathrm{VSA}$ & 320 \\
\hline & CH-H500D32 & & 32 & $10 \mathrm{VSA}$ & 403 \\
\hline \multirow{6}{*}{$\begin{array}{c}\text { Cyclic loading at large } \\
\text { strain }\end{array}$} & CL-H400D16 & \multirow[t]{3}{*}{ HRB400 } & 16 & $5 \mathrm{VSA}$ & 220 \\
\hline & CL-H400D25 & & 25 & $8 \mathrm{VSA}$ & 320 \\
\hline & CL-H400D32 & & 32 & $10 \mathrm{VSA}$ & 403 \\
\hline & CL-H500D16 & \multirow[t]{3}{*}{ HRB500 } & 16 & $5 \mathrm{VSA}$ & 220 \\
\hline & CL-H400D25 & & 25 & $8 \mathrm{VSA}$ & 320 \\
\hline & CL-H500D32 & & 32 & $10 \mathrm{VSA}$ & 403 \\
\hline
\end{tabular}


Table 6 Loading procedures for specimens under incremental and repeated tensile loadings.

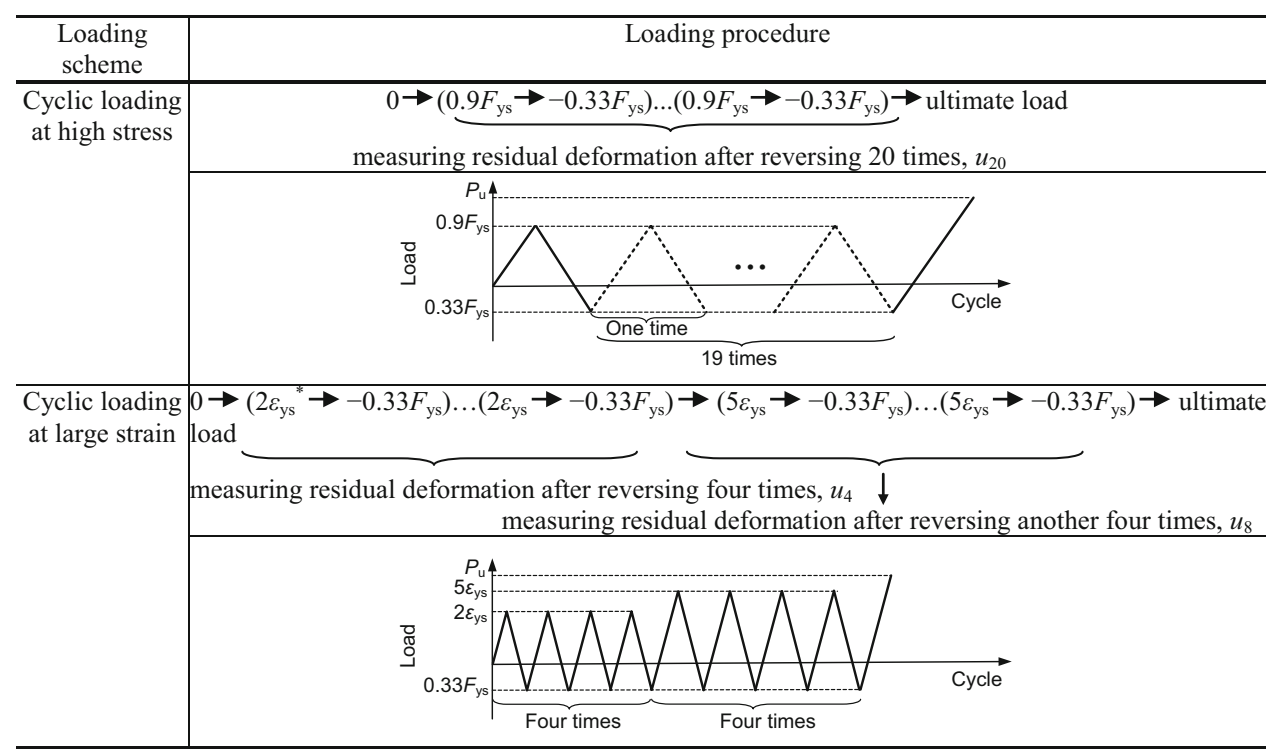

${ }^{*} \varepsilon_{\mathrm{ys}}$ is the yield strain of reinforcing steel bars.
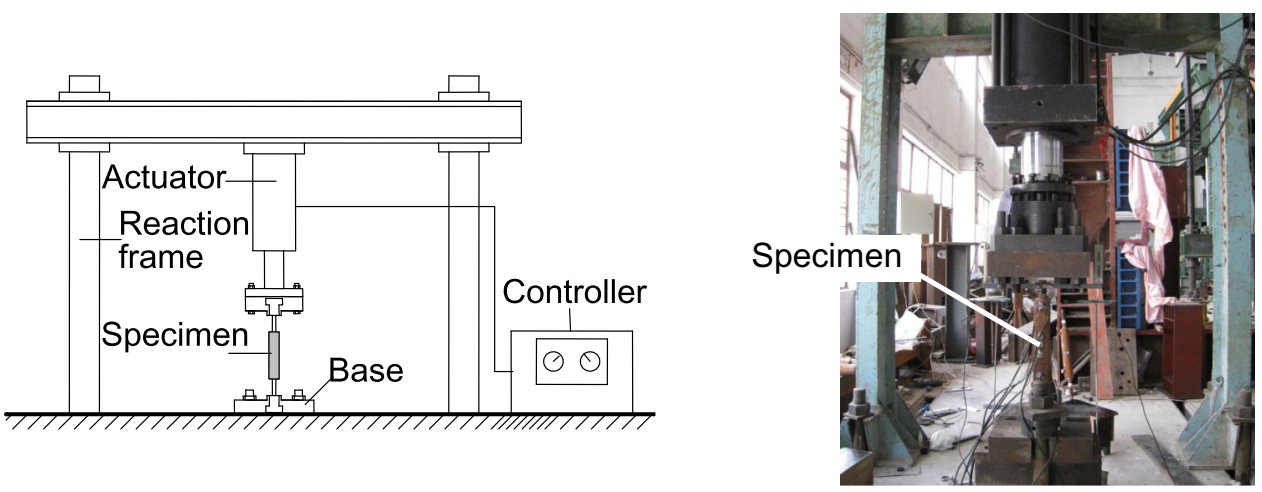

Fig. 4 Test setup for specimens under cyclic loadings at high stress and at large strain.

grout, which can exceed the slip corresponding to peak bond stress and thus reduce the bond. Second, plastic deformation reduces the bar's area which also negatively affects the bond. In addition, the stresses of bars at ultimate loads averaged 92 and $91 \%$ of the ultimate stresses of the embedded bars for the IT- and RT-series specimens, respectively. This meant that repeated loading of about $0.6 F_{\mathrm{ys}}$ had a minor effect on the ultimate loads of the specimens.

\subsubsection{Deformations}

The relative elongations at ultimate loads $\delta_{\mathrm{IT}}$ and $\delta_{\mathrm{RT}}$ presented in Table 7 ranged from 3.7 to $11.0 \%$ with a mean value of about $6.6 \%$, which was significantly less than the ultimate strains of the embedded bars, which varied from $11 \%(0.11)$ to $15 \%(0.15)$ with a mean value of about $12 \%$ as presented in Table 1. This indicated a weak deformation capacity of the splices compared to the bars in ultimate state. Moreover, the relative elongations averaged 6.8 and $6.4 \%$ for the IT- and RT-series specimens, respectively, which showed no obvious differences between the specimens under the two load types.

\subsubsection{Load-Deformation Curves}

Load-deformation responses of the specimens were obtained and typical curves are presented in Fig. 6. Four horizontal lines from the bottom up in each figure correspond to yield loads of bars HRB400 and HRB500 and the ultimate loads of bars HRB400 and HRB500, respectively. Three stages can be recognized from the curves, i.e., elastic, yield and hardening stages. Generally, no undesired brittle failure behavior without yield or hardening stages could be found in this study. Such failure is characterized by bar pullout failure before yielding of the spliced bars in certain specimens, as noted in (Ling et al. 2012). In this study, specimens failed after yielding and at least close to 0.83 (see Table 7) of the ultimate strengths of the connected bars. As a 
Table 7 Test results for specimens under incremental and repeated tensile loadings.

\begin{tabular}{|c|c|c|c|c|c|c|c|c|c|c|c|c|c|}
\hline \multicolumn{2}{|c|}{ Specimen no. } & \multicolumn{2}{|c|}{$\begin{array}{l}\text { Ultimate load } P_{\mathrm{u}} \\
(\mathrm{kN})^{\mathrm{a}}\end{array}$} & \multicolumn{2}{|c|}{$f_{\mathrm{u}} / f_{\text {us }}(\%)^{\mathrm{b}, \mathrm{c}}$} & \multicolumn{2}{|c|}{$\begin{array}{l}\text { Av. bond strength } \\
\tau_{\mathrm{u}}(\mathrm{MPa})^{\mathrm{d}}\end{array}$} & \multicolumn{2}{|c|}{ Elongation $(\mathrm{mm})$} & \multicolumn{2}{|c|}{\begin{tabular}{|c|}
$\begin{array}{c}\text { Relative elongation } \\
(\%)\end{array}$ \\
\end{tabular}} & \multicolumn{2}{|c|}{ Failure mode } \\
\hline IT- & RT- & IT- & RT- & IT- & RT- & IT- & RT- & $u_{\mathrm{IT}}$ & $u_{\mathrm{RT}}$ & $\delta_{\mathrm{IT}}$ & $\delta_{\mathrm{RT}}$ & IT- & RT- \\
\hline \multicolumn{2}{|c|}{ H400D14 } & 88 & 88 & 0.87 & 0.87 & - & - & 20.6 & 22.3 & 7.5 & 8.1 & $\begin{array}{c}\text { Bar } \\
\text { fracture }\end{array}$ & $\begin{array}{c}\text { Bar } \\
\text { fracture }\end{array}$ \\
\hline \multicolumn{2}{|c|}{ H400D16 } & 126 & 125 & 0.91 & 0.91 & - & - & 21.5 & 21.9 & 7.6 & 7.7 & $\begin{array}{c}\text { Bar } \\
\text { fracture }\end{array}$ & $\begin{array}{l}\text { Bar } \\
\text { fracture }\end{array}$ \\
\hline \multicolumn{2}{|c|}{ H400D20 } & 187 & 178 & 1.04 & 1.00 & 26.2 & 25.0 & 40.5 & 21.8 & 11.0 & 5.9 & $\begin{array}{c}\text { Bar pull- } \\
\text { out }\end{array}$ & $\begin{array}{c}\text { Bar pull- } \\
\text { out }\end{array}$ \\
\hline \multicolumn{2}{|c|}{ H400D22 } & 229 & 213 & 0.89 & 0.83 & 27.8 & 26.9 & 17.0 & 14.1 & 4.5 & 3.7 & $\begin{array}{c}\text { Bar pull- } \\
\text { out }\end{array}$ & $\begin{array}{c}\text { Bar pull- } \\
\text { out }\end{array}$ \\
\hline \multicolumn{2}{|c|}{ H400D25 } & 303 & 288 & 0.94 & 0.89 & 30.0 & 28.6 & 30.0 & 23.3 & 7.1 & 5.6 & $\begin{array}{c}\text { Bar pull- } \\
\text { out }\end{array}$ & $\begin{array}{c}\text { Bar pull- } \\
\text { out }\end{array}$ \\
\hline \multicolumn{2}{|c|}{ H400D32 } & 463 & 458 & 0.98 & 0.97 & 26.3 & 26.0 & 39.6 & 32.2 & 7.5 & 6.1 & $\begin{array}{c}\text { Bar pull- } \\
\text { out }\end{array}$ & $\begin{array}{c}\text { Bar pull- } \\
\text { out }\end{array}$ \\
\hline \multicolumn{2}{|c|}{ H500D14 } & 104 & 101 & 0.91 & 0.89 & - & - & 18.7 & 17.6 & 6.8 & 6.4 & $\begin{array}{c}\text { Bar } \\
\text { fracture }\end{array}$ & $\begin{array}{l}\text { Bar } \\
\text { fracture }\end{array}$ \\
\hline \multicolumn{2}{|c|}{ H500D16 } & 136 & 140 & 0.88 & 0.91 & - & 32.8 & 14.8 & 19.7 & 5.2 & 6.9 & $\begin{array}{c}\text { Bar } \\
\text { fracture }\end{array}$ & $\begin{array}{c}\text { Bar pull- } \\
\text { out }\end{array}$ \\
\hline \multicolumn{2}{|c|}{ H500D20 } & 222 & 218 & 0.92 & 0.91 & 31.1 & - & 28.5 & 30.6 & 7.7 & 8.3 & $\begin{array}{c}\text { Bar pull- } \\
\text { out }\end{array}$ & $\begin{array}{l}\text { Bar } \\
\text { fracture }\end{array}$ \\
\hline \multicolumn{2}{|c|}{ H500D22 } & 249 & 264 & 0.87 & 0.92 & 31.5 & 32.1 & 16.2 & 29.1 & 4.3 & 7.7 & $\begin{array}{c}\text { Bar pull- } \\
\text { out }\end{array}$ & $\begin{array}{c}\text { Bar pull- } \\
\text { out }\end{array}$ \\
\hline \multicolumn{2}{|c|}{ H500D25 } & 320 & 321 & 0.89 & 0.89 & 31.7 & 31.9 & 24.4 & 21.9 & 5.8 & 5.2 & $\begin{array}{c}\text { Bar pull- } \\
\text { out }\end{array}$ & $\begin{array}{c}\text { Bar pull- } \\
\text { out }\end{array}$ \\
\hline \multicolumn{2}{|c|}{ H500D32 } & 549 & 533 & 0.90 & 0.90 & 32.3 & 30.3 & 36.3 & 27.7 & 6.8 & 5.2 & $\begin{array}{c}\text { Bar pull- } \\
\text { out }\end{array}$ & $\begin{array}{c}\text { Bar pull- } \\
\text { out }\end{array}$ \\
\hline \multicolumn{4}{|c|}{ Mean value (coefficient of variation) } & $\begin{array}{l}0.92 \\
(0.055)\end{array}$ & $\begin{array}{c}0.91 \\
(0.048)\end{array}$ & - & - & - & - & $\begin{array}{l}6.8 \\
(0.28)\end{array}$ & $\begin{array}{l}6.4 \\
(0.22)\end{array}$ & - & - \\
\hline
\end{tabular}

${ }^{\text {a }} P_{\mathrm{u}}$ denotes ultimate load.

${ }^{\mathrm{b}} f_{\mathrm{u}}=4 P_{\mathrm{u}} /\left(\pi d^{2}\right)$.

${ }^{\mathrm{c}} f_{\text {us }}$ means ultimate strength of reinforcing steel bar.

${ }^{\mathrm{d}} \tau_{\mathrm{u}}=P_{\mathrm{u}} /\left(\pi d L_{\mathrm{i}}\right), L_{\mathrm{i}}$ with $i=1$ or 2 means the length of embedded bar that was pulled out. $\tau_{\mathrm{u}}$ was unavailable for splices with bar fracture.

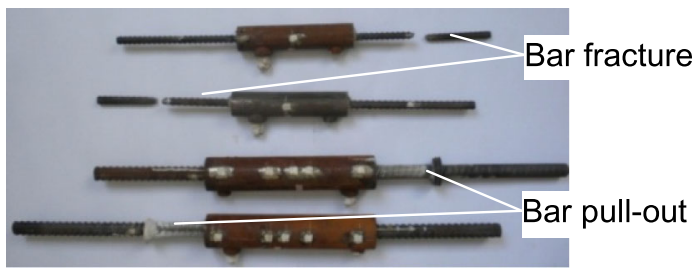

Fig. 5 Two failure modes of specimens under incremental and repeated tensile loadings.

result, the failure was ductile even though the splices underwent bar pull-out. This is also evident from the flattened hardening stages in the load-deformation curves in Fig. 6. Additionally, the unloaded and reloaded paths almost overlapped for the RT-series specimens. Typically, the residual deformations were about $0.09 \mathrm{~mm}$ for specimens RT-H400D25 and RT-H500D25, which was approximately
$5 \%$ of the deformations when splices yielded. Therefore, the residual deformations in RT-series specimens can be ignored for the tested splices.

\subsubsection{Behavior of Coupling Sleeves}

Mechanical behavior of the coupling sleeves was investigated in terms of strain development and peak strain distributions at ultimate loads on their external surfaces both in the longitudinal and transverse directions. As an example, Fig. 7 presents the peak strain distribution on the surface of specimen IT-H400D25. The values on the $x$ axis denote the distances from the narrow end of the sleeve to the observed points. First, it was found that along the longitudinal direction, all coupling sleeves were in tension. The peak strain of each specimen appeared in the midsection and decreased gradually towards the two sleeve ends. Second, in the transverse direction, the strains were relatively small compared to those in the longitudinal direction. Peak strains were 

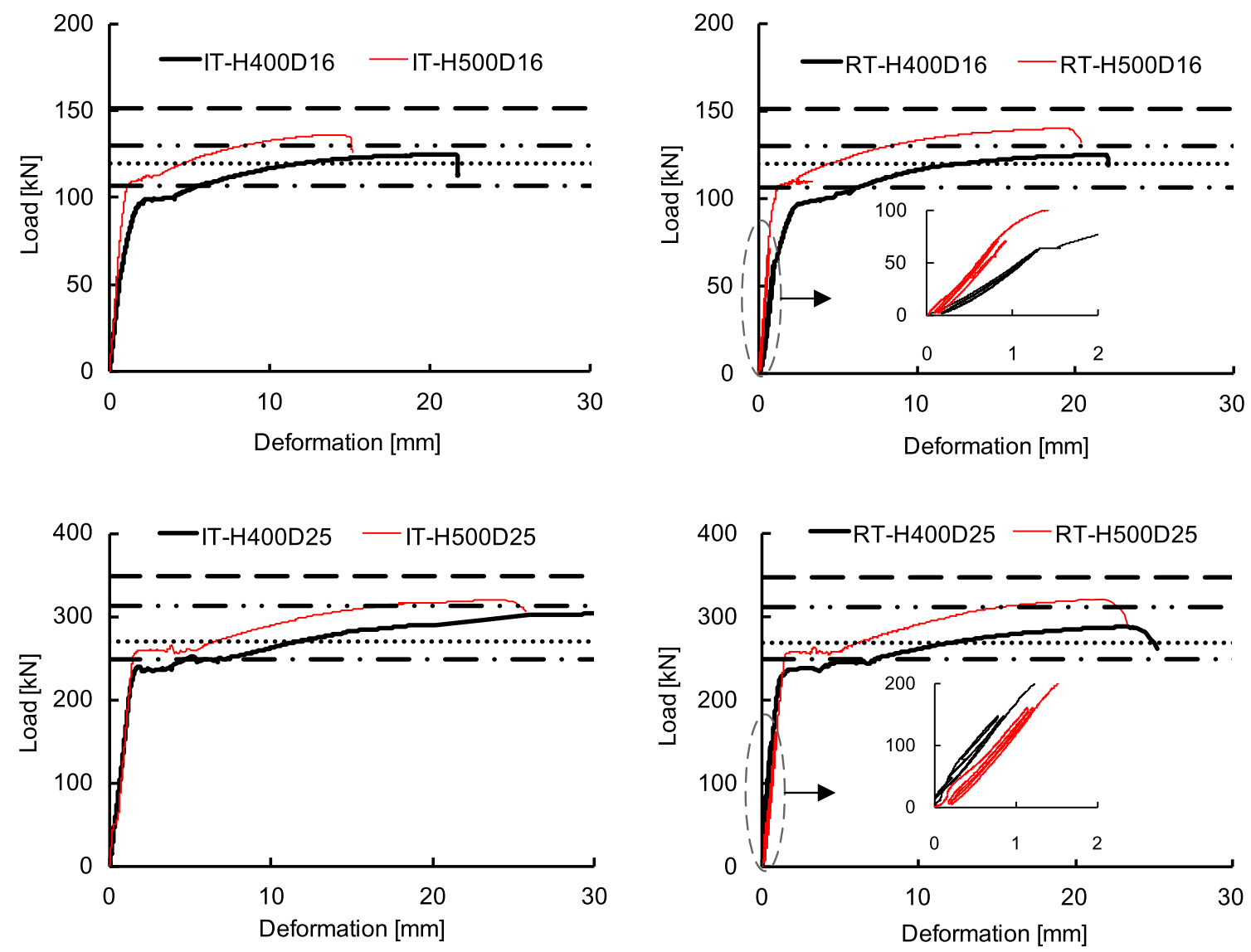

Fig. 6 Typical load-deformation curves for specimens under incremental and repeated tensile loadings.

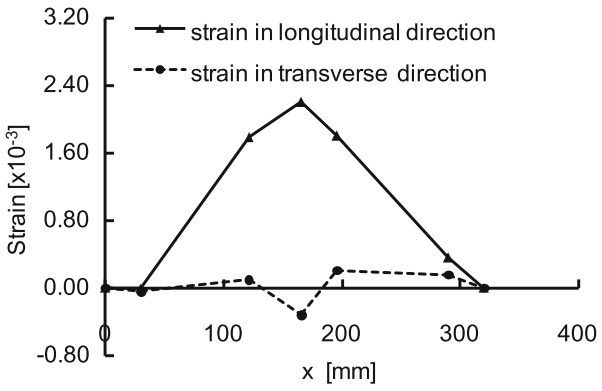

Fig. 7 Peak strain distribution on the external surface of the coupling sleeve of specimen IT-H400D25.

generally located in the midsection but were compressive. Located outside of the central parts, the sleeves were in tension or compression. Finally, the principal strain distributions of all sleeves were calculated based on the strain analysis theory of continuum mechanics by means of strain gauge rosettes. The principal stresses did not exceed their specified tensile strength of $600 \mathrm{MPa}$ with an assumption of the elasticity modulus of $200 \times 10^{3} \mathrm{MPa}$.

These observations can be interpreted as follows. Two spliced bars were disconnected near the middle section of a sleeve. As a result, the middle part of the sleeve carried almost all the accumulative tensile loading transferred from the embedded bar and, therefore, resulted in peak stress. In the transverse direction, the strain condition depended on the combination of two factors. The first one was the Poisson effect because sleeves were tensile loaded longitudinally resulting in transverse shrinkage. The second factor was split expansion in the radial direction induced by the filled grout due to bar-grout bond, which caused the sleeves to dilate transversely. Consequently, different sleeve configurations influenced the two factors, resulting in various strain distributions in the transverse direction which can be different from the observation in this study (Einea et al. 1995; Ling et al. 2012).

\subsection{Specimens Under Cyclic Loadings at High Stress and at Large Strain}

Table 8 summarizes the test results of the CH- and CLseries specimens.

\subsubsection{Failure Modes}

Bar pull-out failure was found for all specimens. Only specimen $\mathrm{CH}-\mathrm{H} 400 \mathrm{D} 16$ formed an exception which failed in bar fracture. In most cases, the failure mode of a specimen was identical to that under tensile loadings.

\subsubsection{Ultimate Loads}

The ultimate loads presented in Table 8 were compared with those of the IT-series specimens as illustrated in Fig. 8. It is evident that the ultimate loads under different loading schemes were almost identical, indicating that the strength degradation of the bar-grout bond of specimens under cyclic loading, if any, was insignificant. 
Table 8 Test results for specimens under cyclic loadings at high stress and at large strain.

\begin{tabular}{|c|c|c|c|c|c|c|c|c|c|c|c|c|}
\hline \multicolumn{2}{|c|}{ Specimen no. } & \multicolumn{2}{|c|}{$\begin{array}{l}\text { Ultimate load } P_{\mathrm{u}} \\
(\mathrm{kN})\end{array}$} & \multicolumn{2}{|c|}{$f_{\mathrm{u}} / f_{\text {us }}(\%)$} & \multicolumn{2}{|c|}{$\begin{array}{c}\text { Av. bond strength } \tau_{\mathrm{u}} \\
(\mathrm{MPa})\end{array}$} & \multicolumn{3}{|c|}{$\begin{array}{c}\text { Relative residual deformation } \\
(\%)\end{array}$} & \multicolumn{2}{|c|}{ Failure mode } \\
\hline $\mathrm{CH}-$ & $\mathrm{CL}-$ & $\mathrm{CH}-$ & $\mathrm{CL}-$ & $\mathrm{CH}-$ & $\mathrm{CL}-$ & $\mathrm{CH}-$ & $\mathrm{CL}-$ & $\delta_{20}$ & $\delta_{4}$ & $\delta_{8}$ & $\mathrm{CH}-$ & $\mathrm{CL}_{-}$ \\
\hline \multicolumn{2}{|c|}{ H400D16 } & 116 & 120 & 0.84 & 0.87 & - & 25.4 & 0.60 & 0.07 & 0.16 & $\begin{array}{l}\text { Bar } \\
\text { fracture }\end{array}$ & $\begin{array}{l}\text { Bar pull- } \\
\text { out }\end{array}$ \\
\hline \multicolumn{2}{|c|}{ H400D25 } & 290 & 291 & 0.90 & 0.90 & 27.6 & 25.7 & 0.06 & 0.03 & 0.15 & $\begin{array}{c}\text { Bar pull- } \\
\text { out }\end{array}$ & $\begin{array}{l}\text { Bar pull- } \\
\text { out }\end{array}$ \\
\hline \multicolumn{2}{|c|}{ H400D32 } & 482 & 478 & 1.02 & 1.02 & 27.4 & 25.9 & 0.07 & 0.03 & 0.07 & $\begin{array}{c}\text { Bar pull- } \\
\text { out }\end{array}$ & $\begin{array}{l}\text { Bar pull- } \\
\text { out }\end{array}$ \\
\hline \multicolumn{2}{|c|}{ H500D16 } & 134 & 147 & 0.87 & 0.95 & 28.3 & 31.0 & 0.37 & 0.12 & 0.31 & $\begin{array}{c}\text { Bar pull- } \\
\text { out }\end{array}$ & $\begin{array}{l}\text { Bar pull- } \\
\text { out }\end{array}$ \\
\hline \multicolumn{2}{|c|}{ H500D25 } & 306 & 319 & 0.85 & 0.89 & 29.1 & 30.3 & 0.16 & 0.03 & 0.16 & $\begin{array}{c}\text { Bar pull- } \\
\text { out }\end{array}$ & $\begin{array}{l}\text { Bar pull- } \\
\text { out }\end{array}$ \\
\hline \multicolumn{2}{|c|}{ H500D32 } & 525 & 539 & 0.91 & 0.93 & 29.9 & 30.7 & 0.16 & 0.10 & 0.22 & $\begin{array}{c}\text { Bar pull- } \\
\text { out }\end{array}$ & $\begin{array}{l}\text { Bar pull- } \\
\text { out }\end{array}$ \\
\hline \multicolumn{4}{|c|}{ Mean value (coefficient of variation) } & $\begin{array}{c}0.90 \\
(0.074)\end{array}$ & $\begin{array}{c}0.93 \\
(0.056)\end{array}$ & - & - & $\begin{array}{c}0.24 \\
(0.88)\end{array}$ & $\begin{array}{c}0.06 \\
(0.57)\end{array}$ & $\begin{array}{c}0.18 \\
(0.45)\end{array}$ & - & - \\
\hline
\end{tabular}

Meanings of $P_{\mathrm{u}}, f_{\mathrm{u}}, f_{\mathrm{us}}$ and $\tau_{\mathrm{u}}$ see Table 7 .

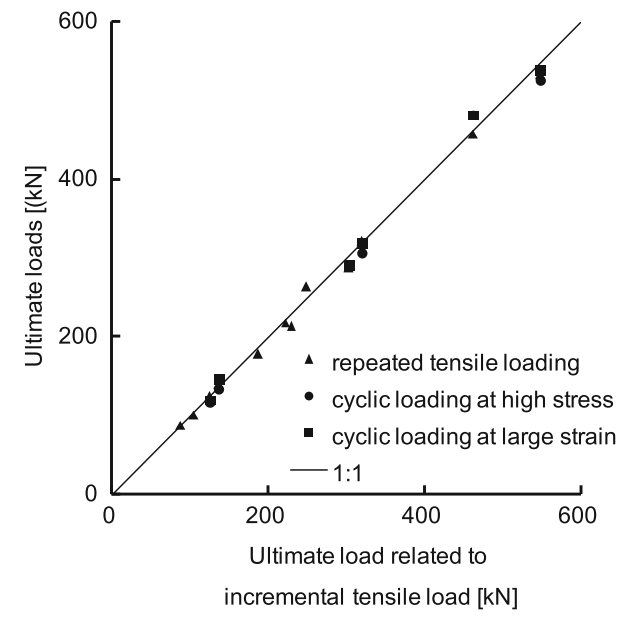

Fig. 8 Comparison of the ultimate loads under different loadings.

\subsubsection{Deformations}

The relative residual deformations $\delta_{20}, \delta_{4}$ and $\delta_{8}$ presented in Table 8 scattered in ranges of 0.06 to $0.60,0.03$ to $0.12 \%$, and $0.07-0.31 \%$, respectively. This implied appreciable residual deformations concerning grout-bar bond for the $\mathrm{CH}$ - and CL-series specimens, compared to yield strains of about $0.25 \%$ for the embedded bars.

\subsubsection{Load-Deformation Curves}

Figures 9 and 10 present the typical load-deformation curves for specimens CH-H400D16 and CL-H400D16, respectively. First, it was found that the load-deformation responses featured a significant pinching effect because the curves contained approximately horizontal sections near the origin, and the hysteresis loops were severely 'pinched'. The pinching effect is an important issue associated with RC

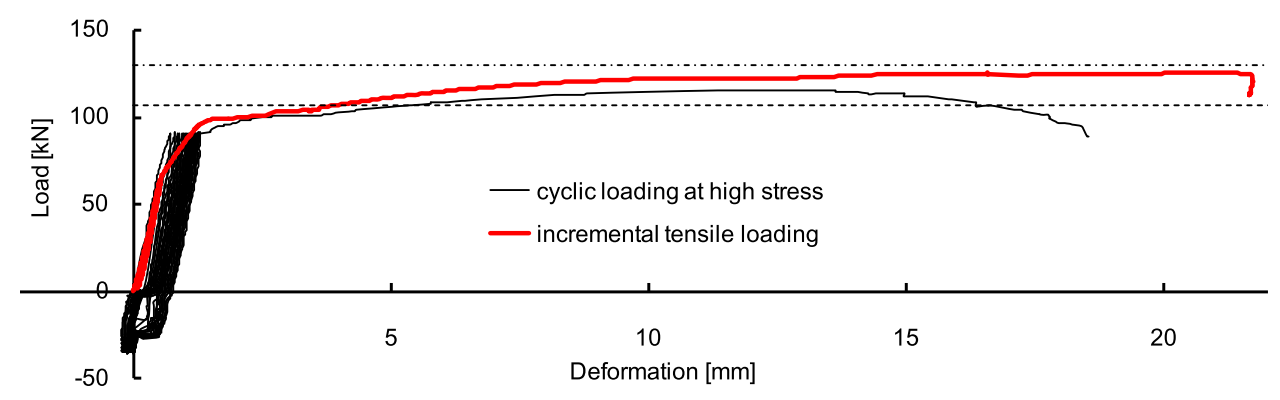

Fig. 9 Load-deformation curves for specimens CH-H400D16 under cyclic loading at high stress. 


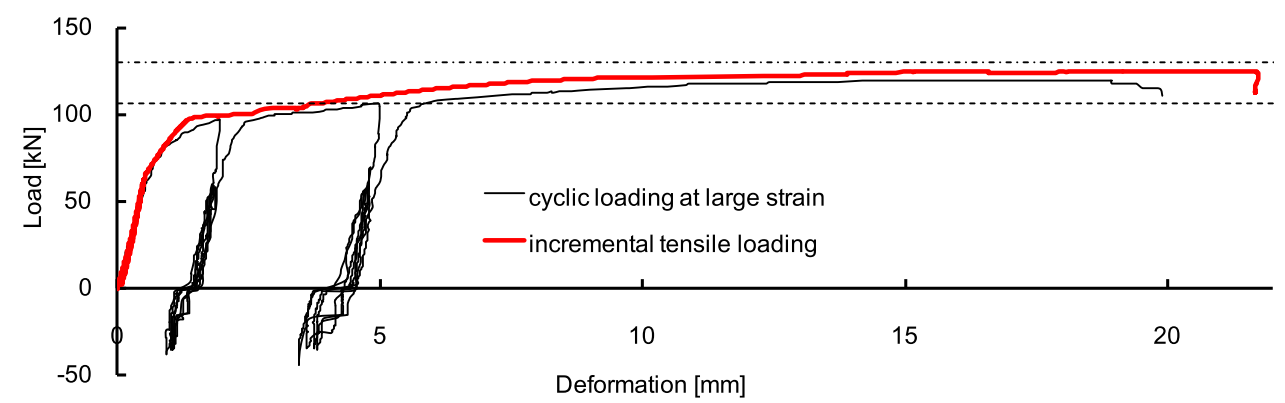

Fig. 10 Load-deformation curves for specimens CL-H400D16 under cyclic loading at large strain.

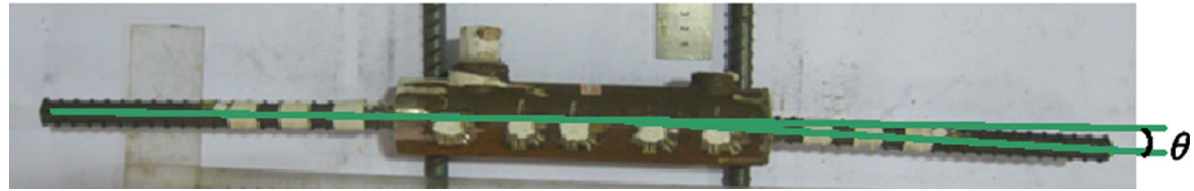

Fig. 11 Misalignment of two spliced bars.

structural members under cyclic loading, generally resulting in reduced ductility and energy dissipation capacities. The pinching effect is believed to be caused by opening and closing of concrete cracks, and by the concrete-bar bond behavior in loading, unloading, and reverse loading as well (Kim 2016). This effect has been observed in a previous study (Hayashi et al. 1997) and is also similar to the behavior of a reinforcing steel bar anchored in concrete under cyclic loading (Model Code 2010). Second, the stiffness degraded gradually, which led to an increase in residual deformation. Finally, the shape of the load-deformation curves for specimens under cyclic loadings were similar to those under incremental tensile loading. These findings formed a basis for presenting the stress-strain relationship of the splices under cyclic loadings.

\subsection{Discussion}

The ultimate load of a splice was less than that of the connected bars, i.e., with averages of about 92, 91, 90 and $93 \%$ of the ultimate load of the connected bar for the IT-, RT-, CH- and CL-series specimens, respectively. The main reasons are believed to be due to the failure modes, misalignment and offset of the embedded bars (Jansson 2008; Ling et al. 2012). The dominant failure mode of the naked plain bars in tensile tests was bar fracture, while the failure mode of most of the splices was bar pull-out associated with relatively low ultimate strengths. The misalignment and offset generated secondary moments, which led to nonuniform stress distribution in the critical section of the connected bars. This caused local and earlier failure compared to the case of purely axial loading. As a result, the ultimate strengths and ultimate strains of the splices decreased. Figure 11 illustrates an example of misalignment. The measured misalignment angles in this study ranged from $0.23^{\circ}$ to $3.27^{\circ}$ and the offsets were not available due to measurement difficulties.
Additionally, the ultimate deformation capacities of the splices were not as strong as those of the connected bars, as mentioned in Sects. 3.1.3 and 3.2.3. The reasons for these differences are believed to be the relatively weak deformation capacity of the sleeve region, misalignment, and offset of the bars.

Furthermore, appreciable distinctions of ultimate deformation were found between the splices with two different failure modes. For IT- and RT-series specimens with bar fracture, the relative elongations at ultimate loads ranged from 5.2 to $8.3 \%$ with an average of $7.0 \%$. However, for IT- and RT-series specimens with bar pull-out, corresponding values varied from 3.7 to $11.0 \%$ with an average of $6.3 \%$. These results were consistent with the understanding that the deformation capacities of bars were better than those of the sleeve regions (JGJ355-2015 2015). Based on these findings, it was suggested to pursue the failure mode of bar fracture instead of bar pull-out in the product design process to make full use of the deformation capacities of the bars.

Besides, experimental results from tests on all 36 specimens indicated that each splice, in tension, developed more than $100 \%$ of the specified tensile strength of the connected bar, and also more than $125 \%$ of the specified yield strength of the connected bar. This means that all specimens met the requirements of Type 2 splices according to AC133 (2014).

Finally, the mechanical performance of the splices, e.g., the ultimate strengths and ultimate deformation capacities, was relatively weak compared to that of the reinforcing steel bars. This may lead to performance variation in the plastic hinge zones of precast structural members in which grouted splices are used. Particularly, in earthquake-prone areas, the plastic hinge zones must resist earthquake-induced deformations and stresses. The performance of the plastic hinge zones partially depend on the mechanical performance of the reinforcement and the grouted splices (Ameli et al. 2015). However, this issue is beyond the scope of this study and needs further research. 


\section{Stress-Strain Relationships}

\subsection{For Splices Under Tensile Loadings}

Under incremental and repeated tensile loadings, the splices behaved similar to the connected bars. Load-deformation curves of the splices and bars generally consisted of three stages, i.e., an elastic stage, a yield plateau and a hardening stage. Moreover, almost no strength and stiffness degradations were found for the RT-series splices compared to the IT-series splices where stress was no more than $0.6 f_{\mathrm{ys}}$. However, primary differences existed between the two curves of the splices and bars. As presented in Table 9, the elasticity moduli, yield strengths, yield plateau lengths, ultimate strengths, and ultimate strains (i.e., relative elongations at ultimate loads) of the splices were reduced on average by about $9,8,63,8$, and $44 \%$ compared to those of the bars, respectively, when a gauge length of $L_{3}$ was considered for comparison. As a result, the stress-strain relationship for the splices under incremental and repeated tensile loadings can be expressed in a form similar to that for reinforcing steel bars with consideration of the above differences.

\subsection{For Splices Under Cyclic Loadings at High Stress and at Large Strain}

Pinching effect and stiffness degradation were the main characteristics for the $\mathrm{CH}$ - and CL-series splices. These features were similar to those of bond stress-slip behavior between embedded reinforcing steel bars and concrete under cyclic loading. The analytical model for bond stress-slip behavior proposed in (Teng and Zou 1996) appropriately considers these characteristics and, therefore, was used as a basis for developing a stress-strain relationship of the tested splices.

Figure 12 presents the profile of stress-strain curves for splices under cyclic loadings at high stress and at large strain. The thick solid skeleton lines are composed of three line segments (segment $O F^{\prime}, F^{\prime} G^{\prime}$ and $G^{\prime} W$ ), which can be determined from test results of the splices under incremental tensile loading, as described in Sect. 4.1 for the splices used in this study. For the first loading, elastic behavior is assumed if the stress was not beyond $0.9 f_{\mathrm{y}}$ and then unloading. Otherwise, reversed characteristics are expressed as follows:

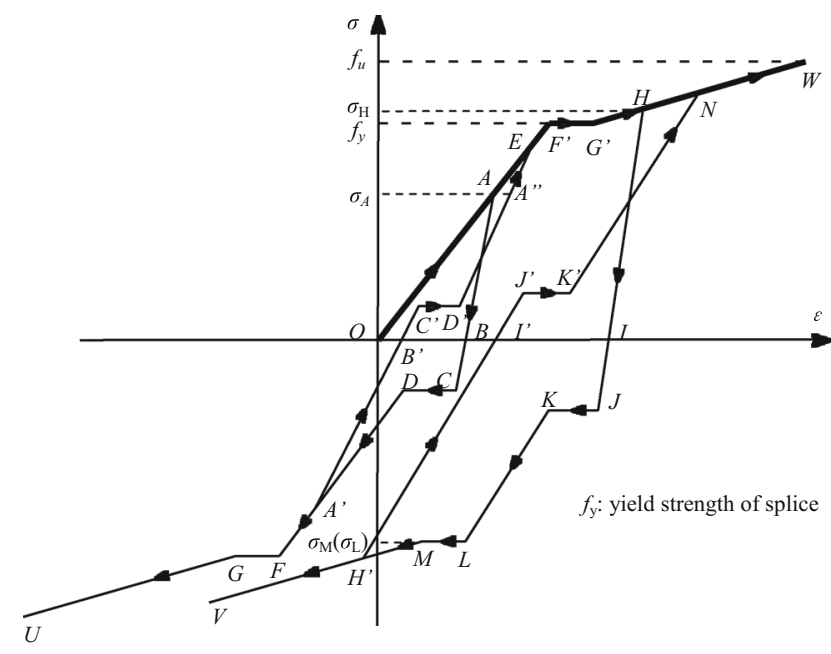

Fig. 12 Stress-strain curves for specimens under cyclic loadings at high stress and at large strain.

Table 9 Comparison of parameters between splices and bars.

\begin{tabular}{c|c|c|c|c}
\hline Specimen No. & $E / E_{\mathrm{s}}$ & $f_{\mathrm{y}} / f_{\mathrm{ys}}$ & $\Delta \varepsilon_{\mathrm{y}} / \Delta \varepsilon_{\mathrm{ys}}$ & 0.34 \\
\hline \hline IT-H400D14 & 0.92 & 0.82 & 0.35 & 0.63 \\
\hline IT-H400D16 & 0.87 & 0.88 & 0.32 & 0.69 \\
\hline IT-H400D20 & 0.72 & 1.10 & 0.30 & 0.35 \\
\hline IT-H400D22 & 0.89 & 0.91 & 0.25 & 0.59 \\
\hline IT-H400D25 & 0.73 & 0.93 & 0.54 & 0.63 \\
\hline IT-H400D32 & 0.95 & 1.01 & 0.31 & 0.57 \\
\hline IT-H500D14 & 1.06 & 0.84 & 0.44 & 0.43 \\
\hline IT-H500D16 & 0.92 & 0.87 & 0.48 & 0.70 \\
\hline IT-H500D20 & 0.90 & 0.88 & 0.41 & 0.39 \\
\hline IT-H500D22 & 0.97 & 0.88 & 0.29 & 0.48 \\
\hline IT-H500D25 & 0.92 & 0.93 & 0.38 & 0.57 \\
\hline IT-H500D32 & 1.01 & 0.98 & $0.92(0.09)$ & $0.23)$ \\
\hline Mean value (coefficient of & $0.91(0.11)$ & & $0.21)$ \\
\hline variation) & & & & 0.56 \\
\hline
\end{tabular}

Data for $f_{\mathrm{u}} / f_{\mathrm{us}}$ could be found in Table 7 . 
(1) First loading beyond $0.9 f_{\mathrm{y}}$ (segment $O A$ )

The splice is first elastically loaded to point $A$ of stress $\sigma_{\mathrm{A}}$ and strain $\varepsilon_{\mathrm{A}}$ with elasticity modulus $E$, in which $\sigma_{\mathrm{A}}$ is greater than $0.9 f_{\mathrm{y}}$ :

$\varepsilon_{\mathrm{A}}=\frac{\sigma_{\mathrm{A}}}{E}$

(2) First positive unloading (segment $A B$ )

For the first positive unloading from point $A$ to point $B$ along with the stresses reducing to 0 , a modulus $E_{2}$ in unloading was obtained from tests.

(3) First negative loading (segment $B C D A^{\prime}$ )

The splice is negatively loaded from point $B$ to $C$ with the modulus $E_{2}$. Afterwards, the strain decreases rapidly from point $C$ to $D$ due to the pinching effect. The splice is then negatively loaded from point $D$ to control point $A^{\prime}$ (stress level was controlled by no more than $-0.33 f_{\mathrm{y}}$ with a modulus of $E_{3}$ in the tests). The relationships between these parameters are:

$\sigma_{\mathrm{C}}=-\alpha_{\mathrm{f}} \sigma_{\mathrm{A}}$

$\varepsilon_{\mathrm{C}}=\varepsilon_{\mathrm{A}}+\frac{\sigma_{\mathrm{C}}-\sigma_{\mathrm{A}}}{E_{2}}$

$\sigma_{\mathrm{D}}=\sigma_{\mathrm{C}}$

$\varepsilon_{\mathrm{D}}=\varepsilon_{\mathrm{C}}-\Delta \varepsilon_{-}$

$\varepsilon_{\mathrm{A}^{\prime}}=\varepsilon_{\mathrm{D}}+\frac{\sigma_{\mathrm{A}^{\prime}}-\sigma_{\mathrm{D}}}{E_{3}}$

where $\alpha_{\mathrm{f}}$ denotes the stress coefficient due to negative friction, and $\Delta \varepsilon_{-}$means horizontal strain length under negative loading due to the pinching effect.

(4) Negative unloading and reloading (segment $A^{\prime} B^{\prime} C^{\prime} D^{\prime} A^{\prime \prime}$ )

Similar to positive unloading and negative loading (segment $A A B C D A^{\prime}$ ), the relations between the related parameters are:

$\sigma_{\mathrm{C}^{\prime}}=-\alpha_{\mathrm{f}}^{\prime} \sigma_{\mathrm{A}^{\prime}}$

$\varepsilon_{\mathrm{C}^{\prime}}=\varepsilon_{\mathrm{A}^{\prime}}+\frac{\sigma_{\mathrm{C}^{\prime}}-\sigma_{\mathrm{A}^{\prime}}}{E_{4}}$

$\sigma_{\mathrm{D}^{\prime}}=\sigma_{\mathrm{C}^{\prime}}$

$\varepsilon_{\mathrm{D}^{\prime}}=\varepsilon_{\mathrm{C}^{\prime}}+\Delta \varepsilon_{+}$

$\varepsilon_{\mathrm{A}^{\prime \prime}}=\varepsilon_{\mathrm{D}^{\prime}}+\frac{\sigma_{\mathrm{A}^{\prime \prime}}-\sigma_{\mathrm{D}^{\prime}}}{E_{1}}$

where $\alpha_{f}^{\prime}$ denotes the stress coefficient due to positive friction, $\Delta \varepsilon_{+}$means horizontal strain length under positive loading due to the pinching effect, $E_{4}$ is the modulus in negative unloading, and $E_{1}$ is the modulus when reloading.

(5) Loops for unloading hysteresis after point $A^{\prime \prime}$ outside hardening stage (after $A^{\prime}$ )
The loop paths following "positive unloading-negative loading-negative unloading-positive reloading” are similar to that of segment $A A B C D A^{\prime} B^{\prime} C^{\prime} D^{\prime} A^{\prime \prime}$.

(6) Loops for loading hysteresis after point $A^{\prime \prime}$ outside hardening stage (after $A^{\prime \prime}$ )

The loading continues to follow the skeleton lines. The coordinate of point $E$ at intersection can be derived from the two straight-lines $O F^{\prime}$ and $D^{\prime} A^{\prime \prime}$ in the strainstress coordinate system.

(7) Unloading and reloading in hardening stage (segment HIJKLMH' $\left.I^{\prime} J^{\prime} K^{\prime} N\right)$

The loop paths are similar to that of $A B C D A^{\prime} B^{\prime} C^{\prime} D^{\prime} E$ with the moduli of $E_{2}, E_{3}, E_{4}$ and $E_{1}$, respectively. Assuming that the yield strength in the negative loading process decreases due to the Bauschinger effect:

$$
\sigma_{\mathrm{L}}=\sigma_{\mathrm{M}}=\sigma_{\mathrm{H}}-2 f_{\mathrm{y}}
$$

the parameters used in the stress-strain relationship, i.e., $f_{\mathrm{y}}$, $f_{\mathrm{u}}, E, E_{\mathrm{h}}, \Delta \varepsilon_{\mathrm{y}}, E_{1}, E_{2}, E_{3}, E_{4}, \alpha_{\mathrm{f}}, \alpha_{\mathrm{f}}^{\prime}, \Delta \varepsilon_{-}, \Delta \varepsilon_{+}$are obtained from test results and are presented in Table 10 .

As an example, Fig. 13 faces the modeled and tested stress-strain curves for specimens CH-H400D16 and CLH400D16. For each specimen, the parameters for skeleton lines $\left(f_{\mathrm{y}}, f_{\mathrm{u}}, E, E_{\mathrm{h}}, \Delta \varepsilon_{\mathrm{y}}\right)$ and the mean values of other parameters $\left(E_{1}, E_{2}, E_{3}, E_{4}, \alpha_{\mathrm{f}}, \alpha_{\mathrm{f}}^{\prime}, \Delta \varepsilon_{-}, \Delta \varepsilon_{+}\right)$were used. In general, the proposed model can appropriately describe the mechanical behavior of splices under cyclic loadings.

\section{Conclusions}

Experimental studies were performed on 36 specimens of grouted splices under four loading schemes involving incremental tensile and repeated tensile loadings, cyclic loadings at high stress and at large strain. The following conclusions can be drawn based on this research:

(1) No appreciable differences were found between the mechanical performance of splices under incremental and repeated tensile loadings. The repeated loading of about $0.6 F_{\text {ys }}$ had a minor effect on the ultimate loads and relative elongations of the splices. The unloading and reloading paths almost overlapped for specimens under repeated tensile loading, which indicated the splices worked well under service loads. In addition, different sleeve configurations influenced the sleeves' strain distributions in the transverse direction.

(2) Mechanical behavior of splices under cyclic loading has a pronounced pinching effect and stiffness degradation. The shape of the load-deformation curves for specimens under cyclic loadings were similar to those under incremental tensile loading. This finding formed a basis for presenting the stress-strain relationship of the splices under cyclic loading. Appreciable residual deformations were found for specimens under cyclic loadings. Degradation of the ultimate strengths and 


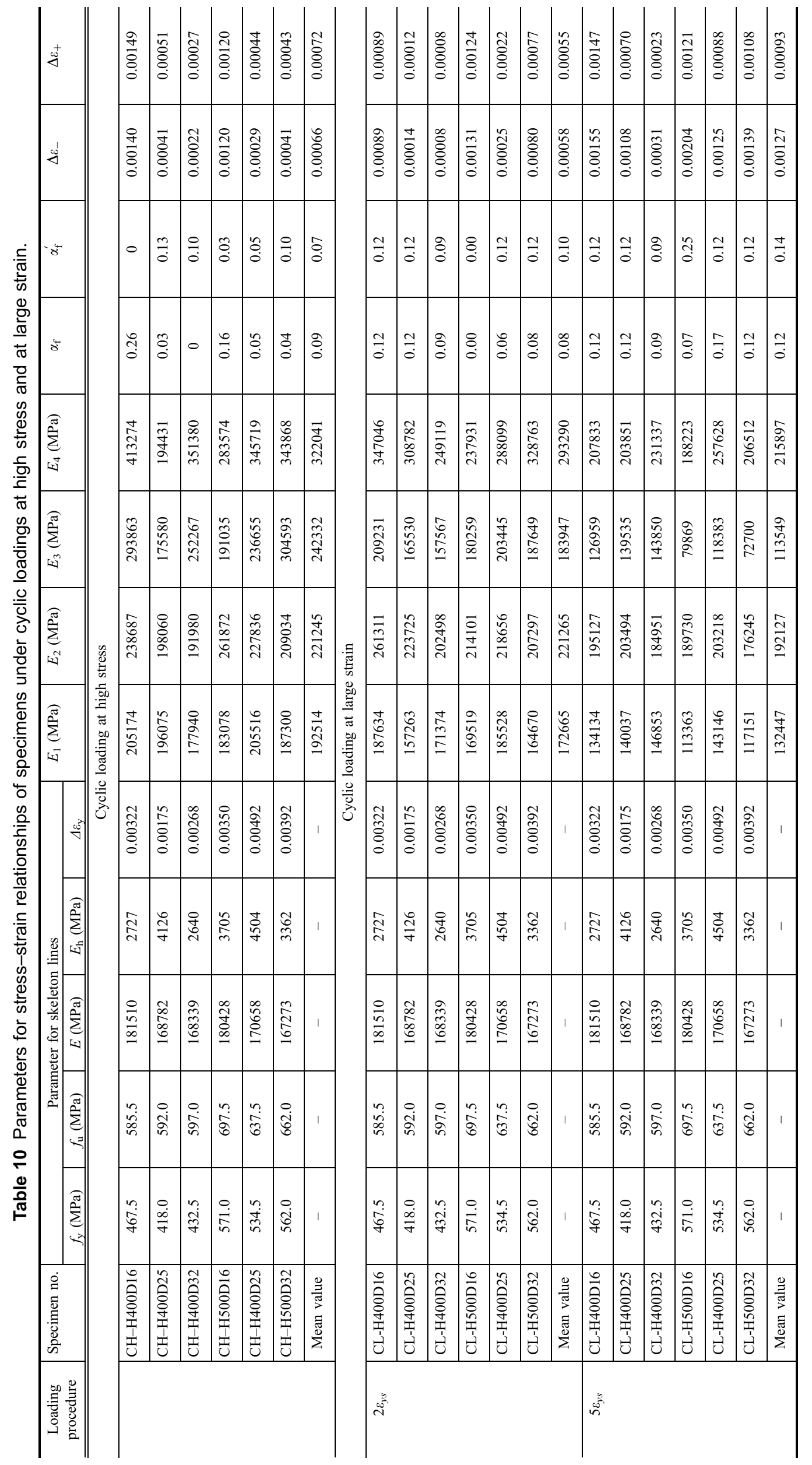



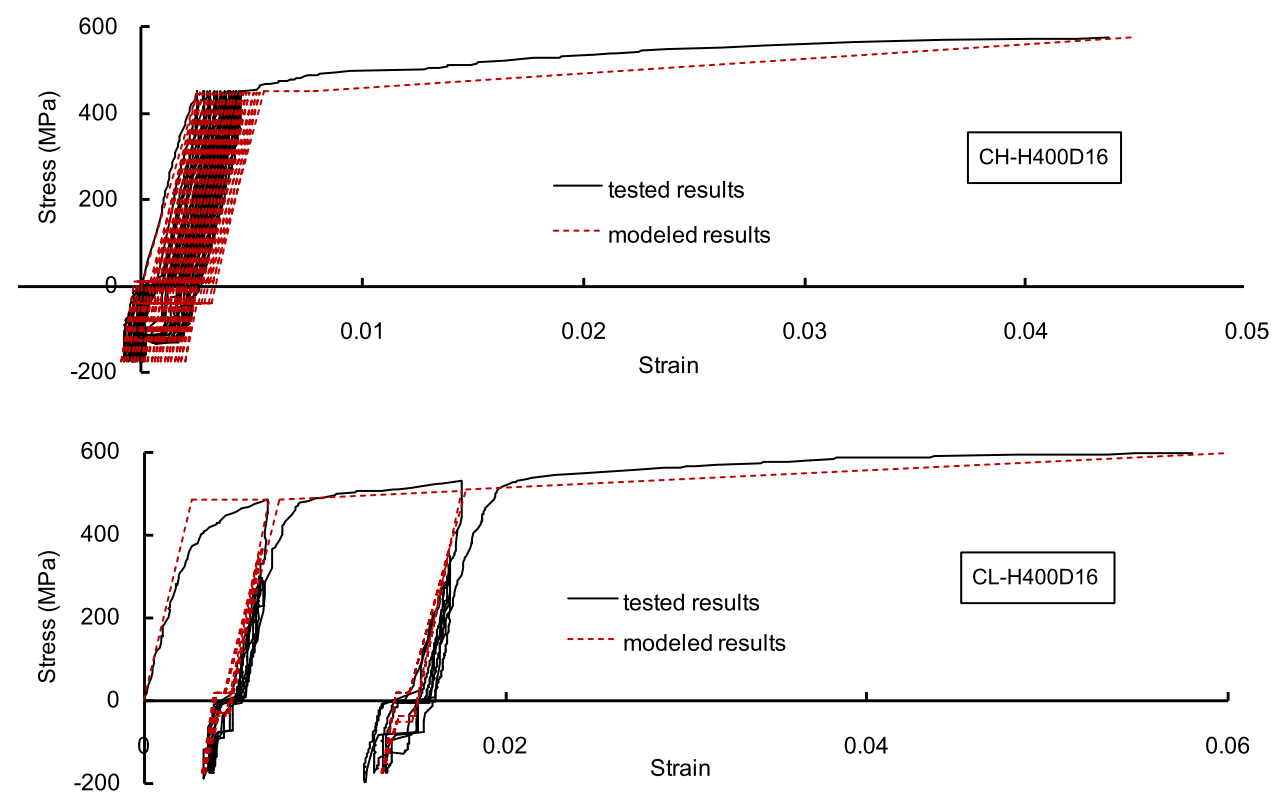

Fig. 13 Modeled and tested stress-strain curves for splices under cyclic loading at high stress and at large strain.

ultimate deformation capacities were not observed compared to specimens under tensile loadings.

(3) Two stress-strain relationships, which considered the main aspects of the mechanical performance, were presented for the splices under tensile loadings and under cyclic loadings.

\section{Acknowledgments}

The authors would like to extend their sincere gratitude to the Kwang-Hua Education Foundation for financial support.

\section{Open Access}

This article is distributed under the terms of the Creative Commons Attribution 4.0 International License (http://creativecommons.org/licenses/by/4.0/), which permits unrestricted use, distribution, and reproduction in any medium, provided you give appropriate credit to the original author(s) and the source, provide a link to the Creative Commons license, and indicate if changes were made.

\section{References}

Ameli, M. J., Parks, J. E., Brown, D. N., \& Pantelides, C. P. (2015). Seismic evaluation of grouted splice sleeve connections for reinforced precast concrete column-to-cap beam joints in accelerated bridge construction. PCI Journal, 60(2), 80-103.

Einea, A., Yamane, T., \& Tadros, M. K. (1995). Grout-filled pipe splices for precast concrete construction. PCI Journal, 40(1), 82-93.
Hayashi, Y., Nakatsuka, T., Miwake, I., \& Suzuki, K. (1997). Mechanical performance of grout-filled coupling steel sleeves under cyclic loads. Journal of Structural and Construction Engineering, Architectural Institute of Japan, 496, 91-98 (in Japanese).

Henin, E., \& Morcous, G. (2015). Non-proprietary bar splice sleeve for precast concrete construction. Engineering Structures, 83, 154-162.

ICC Evaluation Service Inc, AC133. (2014). Acceptance criteria for mechanical connector systems for steel reinforcing bars. Birmingham, AL: ICC Evaluation Service, Inc., AC133.

International Federation for Structural Concrete. (2010). Model code 2010. Lausanne, Switzerland: FIB Bulletin.

Jansson, P. O. (2008). Evaluation of grout-filled mechanical splices for precast concrete construction. Lansing, MI: Michigan Department of Transportation.

JGJ355-2015. (2015). Technical specification for grout sleeve splicing of rebars. Beijing: Ministry of Housing and UrbanRural Development of the People's Republic of China, China Architecture \& Building Press.

Kim, D. K. (2016). Seismic response analysis of reinforced concrete wall structure using macro model. International Journal of Concrete Structures and Materials. doi: 10.1007/s40069-016-0131-1.

Kim, H. K., \& Lee, S. H. (2012). Lateral confining action of mortar-filled sleeve reinforcement splice. Structural Engineering and Mechanics, 41(3), 379-393.

Ling, J. H., Rahman, A. B. A., \& Ibrahim, I. S. (2014). Feasibility study of grouted splice connector under tensile load. Construction and Building Materials, 50, 530-539.

Ling, J. H., Rahman, A. B. A., Ibrahim, I. S., et al. (2012). Behaviour of grouted pipe splice under incremental tensile load. Construction and Building Materials, 33, 90-98.

Ren, W., Sneed, L. H., Yang, Y., \& He, R. (2015). Numerical simulation of prestressed precast concrete bridge deck 
panels using damage plasticity model. International Journal of Concrete Structures and Materials, 9(1), 45-54.

Steuck, K. P., Eberhard, M. O., \& Stanton, J. F. (2009). Anchorage of large-diameter reinforcing bars in ducts. ACI Structural Journal, 106(4), 506-513.
Teng, Z. M., \& Zou, L. X. (1996). Nonlinear finite element analysis of RC members under reversed cyclic loading. China Civil Engineering Journal, 29(2), 19-27 (in Chinese). Yee, A. (1973). New precast prestressed system saves money in Hawaii hotel. PCI Journal, 18(3), 10-13. 